\title{
Designing a device to measure Speed and precision of attacking Skills performance for fencing players
}

\author{
"Dr/Hany Mohamed Zakaria
}

\section{Introduction :}

Physical education fulfill a significant progress in the second half of the $20^{\text {th }}$ century as a result of using science and technology in scientific research specially in measurement and evaluation method as they are the most important support which contribute in physical education progress.

"Mohamed Hassan Alawi", "Mohamed Nasr Eldin Radwan" (1996) show the importance of tests and measurements as they are an important means to measure individual achievement in sport and benefit of training process, also they are an effective means to stimulate motivation for practicing, training and trying to reach higher physical levels.

\section{Research problem :}

"Ebrahim Nabil" (2003), mention that good performance in fencing without precision in scoring touch or performing parry and attack movements or accuracy in moving within fencing strip lead to useless performance as final goal from performing fencing skills is precision of touch in the right place for opponent (1: 40).

Test and measurements considered the most effective evaluation means in sport field in general and specially on fencing as they help in :

- Stimulate motivation for training and learning

- Identify the actual level for fencer and develop strength point and deal with weakness point to achieve higher level.

(*) Lecturer in Educational, psychological and Social Dept. Faculty of Physical Education for Boys- Banha University. 
- Help us in identifying the progress that the player reach by comparing the present level by the previous level.

- Create a competitive spirit between the players

The researcher mention that fencing field have deficiency in modern devices that used in measuring which have negative effect on fencer and affect constructing the training load on a scientific base .

This motivate the researcher try to design an electronic device to measure speed and precision of attacking skills performance for fencing players.

\section{The researcher realize that :}

- When he ask the players to measure speed they concentrate on performing speed only not precision of performance

- When he ask the players to measure precision of performance their speed decrease as they want to have a great score in precision.

- So to keep the measurement the same as the actual state in the match the researcher take into consideration that the designed device must provide him with:

- Precision measure.

- Speed measure.

- Measuring speed and precision of performance in the same time, the researcher use the term "speed specified by precision" in fencing.

\section{Research Importance :}

This research is considered a new scientific attempt in fencing field as the researcher seek to design a device to measure speed and precision of attacking skills performance for fencing players.

- The designed device save the time and effort for fencing trainer 
- The designed device is used for all ages and both gender

- Avoid subjectivity in measuring and directed to objectivity

- Provide a special data base for every player to facilitate following up his training level continually.

- This research may contribute in designing a device with low cost price which increase the opportunity to publicize infeasible price to clubs and youth center.

- This research may allow new research in training and measurement field.

- Considered a mean of individual training in fencing

- A trial to use digital technology in practical application aspect that help on setting up the training process on a scientific bases.

This research has more importance for coaches and players as electronic jacket afford the following:

1- The coach can wear it to realize the actual player level through lessons in the training unit, and in this case the coach will be a positive or negative defender during measurement due to player performance level and aim of measuring.

2- It can be fixed on a model and the player measure the speed and precision of performance under coach control.

\section{* Aim of research:}

\section{This research aim to:}

- Design a device to measure speed and precision of attacking skills performance for fencing players

- Scientific codify to the device

\section{Research assumption:}


- The suggested device can be used to measure speed and precision of performance for fencing players

- The device is characterized by a very high degree in validity and stability.

\section{Research terms:}

\section{1- Electronic device:}

It is a measurement mean made of electronic circuit that was safely designed and used to measure speed and precision of performance for players, the data is printed out immediately after finishing performance for every players through special set up computer program and the measurement saved on data base.

\section{2- "Speed specified by precision" in fencing}

Measuring speed and precision of performance in the same time.

\section{Research procedure}

\section{Research method:}

The researcher used the experimental method as it is appropriate for research nature aiming to design the device, saved computer programes and apply it.

\section{Research sample:}

The research sample was restricted to ration sample to apply measurement used in device validity. Two sample were taken the first is a peculiar sample from fencing national team players (menwomen), the second sample is a practitioner fencing player (un peculiar sample).

Table (1) 


\begin{tabular}{c|c|c|c|c|c}
\hline \hline \multirow{2}{*}{ Sample } & \multirow{2}{*}{ Gender } & \multicolumn{3}{|c|}{ Type of Blade } & \multirow{2}{*}{ Total } \\
\cline { 3 - 6 } Peculiar sample & Men & 3 & 3 & 3 & \multirow{2}{*}{18} \\
\cline { 2 - 5 } & Women & 3 & 3 & 3 & \\
\hline \multirow{2}{*}{ Un peculiar sample } & Men & 3 & 3 & 3 & \multirow{2}{*}{18} \\
\cline { 2 - 5 } & Women & 3 & 3 & 3 & \\
\hline \hline
\end{tabular}

\section{* Data collection}

\section{Reference survey :}

The researcher review the studies and scientific refrences the identity to used tests in measuring speed and precision of attacking skills performance in fencing.

- Specific tools and equipment for the designed device

- Electronic jacket

- Model

- Micro controller unit

- Computer in addition to special programs for measuring speed and precision of performance for fencing players.

- Cables to connect the measurement parts with each other.

\section{Research implementing steps :}

The researcher divided the main experiment into four phases as follows :

\section{- First phase :}

In this phase the researcher design the suggested model used in measuring process and the electronic jacket with the help of a specialized office in designing electronic devices after providing them with all possibilities for the research.

Every point will be explained as follows: 


\section{First : Model}

\section{Technical description for the model}

The designed model is an equivalent shape to the upper part of the body made of plastic strengthed by a polyster layer inside it artificial fibers resistant to pulling to increase toughness of the model when strike with rigid bodies in addition to metallic net from iron fasten by 2 nails from steel used to fix the model on the stand.

- The model heights is $75 \mathrm{~cm}$.

- The length from shoulder region is $48 \mathrm{~cm}$

- The length from the last zone in the upper part of the body $30 \mathrm{~cm}$

- The weight without stand $6 \mathrm{~kg}$

- Max thickness for the body $25 \mathrm{~cm}$

- Min thickness for the body $12 \mathrm{~cm}$.

\section{Stand Description:}

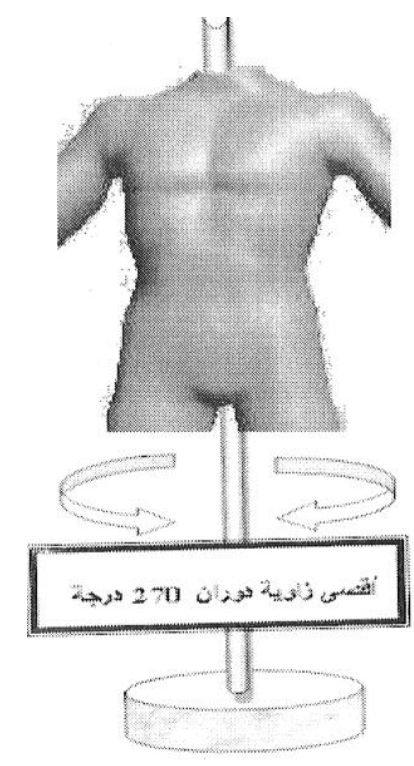

The stand used in scoring speed and precision of attacking skills performance for fencing player was designed to be light in weight to be easily transferred from one place to another and it consist of 2 parts..

\section{(A) The Lower part:}

Consist of vicious tube taking the shape of a pole with height $90 \mathrm{~cm}$ from light iron coated by anti rust paint, the pole is fixed from below in a marble base by a nail passing through strip fixed in the pole by screw tip.

- To tighten the pole it supported by four binding from corners with height $20 \mathrm{~cm}$ to absorb the force occur on the pole during scoring a powerful touch . 
- At the top of the pole there is a stripe made of hard plastic which allow joining the upper and lower part together and easily disconnection once again.

(B) The upper part:

- Consist of a vicious tube from light iron $90 \mathrm{~cm}$ height coated with anti rust paint.

- There is a hard plastic strip fixed at the bottom of the tube of upper part and fitted with the upper stripe fixed in the lower tube connected to the stand base.

- The height of the two parts together is $180 \mathrm{~cm}$ from the base till the top of the stand

- The internal strip available in the model was designed as on placing the model on the stand it tighten both the base and tube together.

- It allow controlling the height of the model from $120 \mathrm{~cm}$ to 180 $\mathrm{cm}$ so we can use the model with junior fencing players

- It allow adjusting the rotation angle of the model within range of $270^{\circ}$.

- The coach can choose the appropriate angle and height for every player individually and the player can deal with the model by using different positions.

\section{Second: The Electronic Jacket}

The target was divided into eight regions as follows:

1- The internal upper quarter at the body contact side

2- The internal upper quarter at an opposite direction to body contact side.

3- The external upper quarter at the body contact side

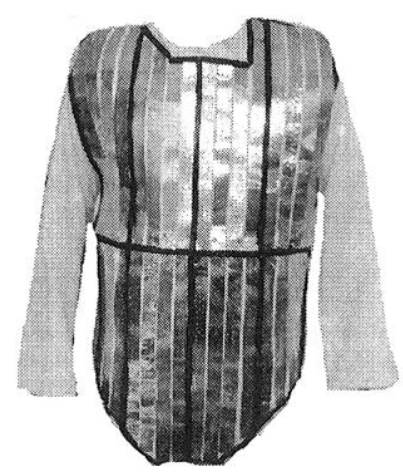


4- The external lower quarter at an opposite direction to body contract

5- The internal lower quarter at the body contact side

6- The internal lower quarter at an opposite side to the body contact.

7- The external lower quarter at the contact body side .

8- The external upper quarter at an opposite side to body contact side .

- Every zone from the eight zone consider a unit for scoring touch in the specific part.

- The scoring unit was divided into four rough copper strip its length $2.5 \mathrm{~cm}$, the distance between every strip is $6 \mathrm{~mm}$.

- The total of the fixed strip on the jacket is (32) copper strip electrically isolated from each other.

- Every strip connected by a wire to the circuit.

- The blade is connected with a ground point when the blade is in contact with any copper strip in the scoring unit it change the voltage from (5) volt to zero volt and transmit this signal to micro controller, so the setup program in micro controller feel the contact of blade to electronic jacked and identify the contact point due to power of flashing light.

\section{Second phase :}

In this phase the researcher implement the control unit. This unit include group of (IC), resistance and output for (USB) to connect the unit to the computer, also output wires connected to copper strips fixed on the electronic jacket and include micro controller. 


\section{The microcontroller function :}

The microcontroller choose and connect due to the order coming from computer, the required touching unit in order, the time set by individual who will apply the measure process due to order coming from computer. The signals come out through flashing light in a specific time (set by coach).As the blade contact the touch unit the device define the speed (by $\mathrm{mm} / \mathrm{sec}$ ) and precision (by degree) for player performance, returning back this data to computer once again. If there is no contact with one of touching unit after the set time for order coming from computer the flashing light closed and send letter $(\mathrm{F})$ to computer which mean (Fail) no response to touch in the set time. The blade will be connected to ground circuit to give zero volt other wise it will gives (5) volt input.

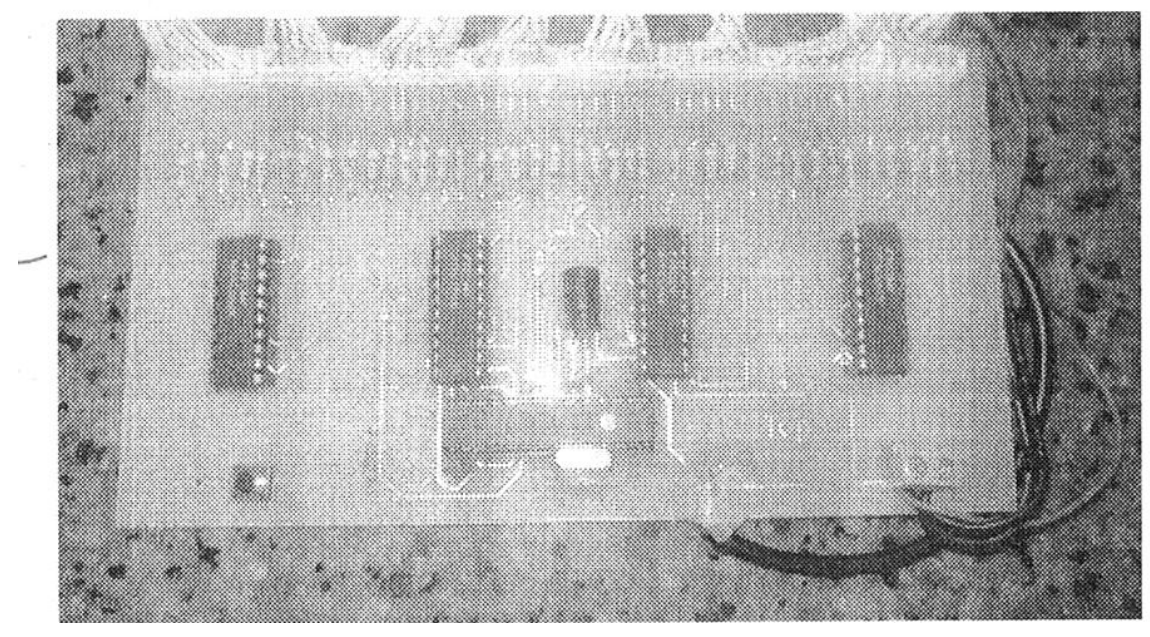

\section{The Third Phase :}

This phase was implemented at the same time of the first and second phase due to relation of the components of the device to the computer programes designed to measure speed and precision of attacking skills performance. The researcher identify the main points and steps with the engineers to specify the output, input requirements, application contents, designing the data base, he apply a complete measurement for speed and precision of players performance. The researcher will demonstrate the special measurement application . 


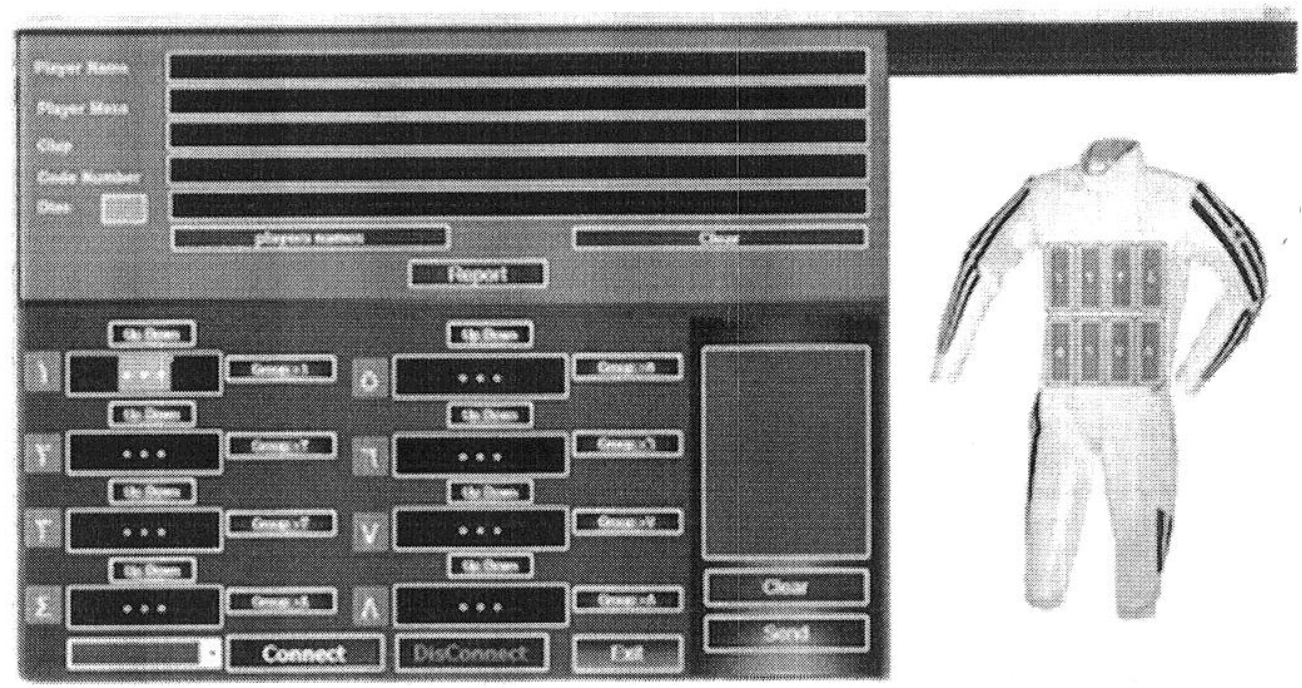

\section{The Fourth Phase:}

1- Applying differentiation validity between two groups one of them is peculiar (National team), the other is unpeculair (practitioner)

2- Applying device stability by Test - Re Test".

3- Applying criterion validity between measurement results for the designed device and motion analysis results for speed and precision of attacking skills performance for fencing players.

\section{First : Validity :}

The researcher use differentiation validity between two groups one of them peculiar group consist of (18) players (9men- 9 women) from Egypt National team, the other is un peculiar group consist of (18) junior player. 


\section{Table (2)}

Arithmatic mean, standard deviation, (T) value between peculiar and un peculiar group to measure speed and precision of attacking skills performance for fencing players

$$
\mathrm{N}_{1}=\mathrm{n}_{2}=18
$$

\begin{tabular}{l|l|c|c|c|c|c}
\hline \hline \multirow{2}{*}{ Test } & \multicolumn{2}{|c|}{ Peculiar group } & \multicolumn{2}{|c|}{$\begin{array}{c}\text { Un peculiar } \\
\text { group }\end{array}$} & $\begin{array}{l}\text { Difference } \\
\text { between } \\
\text { average }\end{array}$ & $\begin{array}{c}\text { (T) } \\
\text { value }\end{array}$ \\
\cline { 2 - 7 } & $\mathrm{M}$ & $\mathrm{D}$ & $\mathrm{M}$ & $\mathrm{D}$ & \\
\hline $\begin{array}{l}\text { 1- Speed of scoring touch } \\
\text { from stretching arm }\end{array}$ & 0.768 & 0.154 & 1.923 & 0.236 & -1.15 & 17.395 \\
\hline $\begin{array}{l}\text { 2- Precision of scoring touch } \\
\text { from stretching arm }\end{array}$ & 7.111 & 1.023 & 2.78 & 1.215 & 4.333 & 11.575 \\
\hline $\begin{array}{l}\text { 3- Speed of scoring touch } \\
\text { from Lunge }\end{array}$ & 1.095 & 0.134 & 2.13 & 0.285 & -1.118 & 15.058 \\
\hline $\begin{array}{l}\text { 4-Precision of scoring touch } \\
\text { from Lunge }\end{array}$ & 7.333 & 0.970 & 2.556 & 1.504 & 4.778 & 11.327 \\
\hline $\begin{array}{l}\text { 5- Speed of scoring touch } \\
\text { from step and Lunge }\end{array}$ & 1.876 & 0.389 & 2.87 & 0.32 & -0.996 & 7.273 \\
\hline $\begin{array}{l}\text { 6-Precision of scoring touch } \\
\text { from step and lunge }\end{array}$ & 7.556 & 0.856 & 2.111 & 1.605 & 5.444 & 12.702 \\
\hline
\end{tabular}

Schedule $(\mathrm{T})$ Value on 0.05 significant level $=2.03$

Table (2) show that the calculated (T) value between the two groups in the choosen tests was between 7.273-17.395 at (0.05) significant level which indicate that there are a statistical significant difference between the two groups in behalf to the peculiar group which indicate the ability of the device to differentiate in the research test. 


\section{Second: Stability :}

The researcher confirm the stability of device result for speed and precision of attacking skills performance for fencing players by "Test - Retest" on a sample of (36) players with range of 10 days between the two test.

\section{Table (3)}

Correlation coefficient between first application and second application to calculate the stability of measuring speed and precision of attacking skills performance for fencing players

$$
\mathrm{N}=36
$$

\begin{tabular}{l|c|c|c|c|l}
\hline \hline \multirow{2}{*}{ Test } & \multicolumn{2}{|c|}{$\begin{array}{c}\text { First } \\
\text { applications }\end{array}$} & \multicolumn{2}{c|}{$\begin{array}{c}\text { Second } \\
\text { application }\end{array}$} & \multirow{2}{*}{$($ T) value } \\
\cline { 2 - 6 } & $\mathrm{M}$ & $\mathrm{D}$ & $\mathrm{M}$ & $\mathrm{D}$ & \\
\hline $\begin{array}{l}\text { 1- Speed of scoring touch from } \\
\text { stretching arm }\end{array}$ & 0.768 & 0.154 & 0.761 & 0.148 & $0.996^{*}$ \\
\hline $\begin{array}{l}\text { 2- Precision of scoring touch from } \\
\text { stretching arm }\end{array}$ & 7.111 & 1.023 & 7.222 & 1.003 & $0.892^{*}$ \\
\hline 3- Speed of scoring touch from Lunge & 1.095 & 0.134 & 1.0 & 0.137 & $0.987^{*}$ \\
\hline $\begin{array}{l}\text { 4-Precision of scoring touch from Lunge } \\
\text { 5- Speed of scoring touch from step and Lunge }\end{array}$ & 7.333 & 0.970 & 7.444 & 0.922 & $0.877^{*}$ \\
\hline $\begin{array}{l}\text { 6-Precision of scoring touch from step } \\
\text { and lunge }\end{array}$ & 7.556 & 0.389 & 1.67 & 0.390 & $0.99 *$ \\
\hline
\end{tabular}

Schedule (R) Value in (0.05) significant level $=0.325$

Table (3) show that the correlation coefficient value between the first application and the second application is between (0.837$0.997)$ and its value is bigger than schedule $(\mathrm{R})$ value at $(0.05)$ significant level which indicate the stability of the device in he research test. 


\section{Criterion Validity :}

\section{Table (4)}

\section{Correlation coefficient between designed device results and motion analysis to speed and precision of attacking skill performance for fencing players}

\begin{tabular}{|c|c|c|c|c|c|c|c|}
\hline \multirow{2}{*}{ Tests } & \multicolumn{2}{|c|}{ Device result } & \multicolumn{2}{|c|}{ Analysis result } & \multirow{2}{*}{$\begin{array}{c}\text { Difference } \\
\text { between } \\
\text { average }\end{array}$} & \multirow{2}{*}{$\begin{array}{l}(\mathbf{R}) \\
\text { Value }\end{array}$} & \multirow{2}{*}{$\begin{array}{l}(\mathbf{T}) \\
\text { Value }\end{array}$} \\
\hline & M & D & M & D & & & \\
\hline $\begin{array}{l}\text { 1-Speed of scoring touch } \\
\text { from stretching arm }\end{array}$ & 0.729 & 0.156 & 0.722 & 0.148 & -0.007 & $0.997 *$ & 0.195 \\
\hline $\begin{array}{l}\text { 2-Precision of scoring } \\
\text { touch from stretching arm }\end{array}$ & 7.333 & 1.000 & 7.333 & 1.000 & - & $1.00 *$ & - \\
\hline $\begin{array}{l}\text { 3-Speed of scoring touch } \\
\text { from Lunge }\end{array}$ & 1.045 & 0.105 & 1.38 & 0.101 & -0.007 & 0.169 & \\
\hline $\begin{array}{l}\text { 4-Precision of scoring } \\
\text { touch from Lunge }\end{array}$ & 7.111 & 1.054 & 7.111 & 1.054 & - & $1.00^{*}$ & - \\
\hline $\begin{array}{l}\text { 5-Speed of scoring touch } \\
\text { from step and Lunge }\end{array}$ & 1.894 & 0.411 & 1.884 & 0.404 & -0.010 & $0.999^{*}$ & 0.172 \\
\hline $\begin{array}{l}\text { 6-Precision of scoring } \\
\text { touch from step and Lunge }\end{array}$ & 7.556 & 0.882 & 7.556 & 0.882 & - & $1.00 *$ & - \\
\hline
\end{tabular}

Schedule $(\mathrm{R})$ value at $(0.05)$ significant level $=0.468$

Schedule $(\mathrm{T})$ value at $(0.05)$ significant level $=2.12$

Table (4) show that the calculated (R) value is bigger than schedule (R) value, also table (4) show that calculated (T)value is smaller than schedule $(\mathrm{T})$ value which indicate that there is no significant statistical difference between measuring results for attacking skills performance by using designed device and analysis result by using computer, this show the validity of the device, its measurement ability and that it is applicable. 


\section{Execution Description on the device :}

\section{First : How the device work}

- The coach choose the appearance of flashing light in the order he demand and no order is recommended, it is allowed for the coach to repeat flashing light more than once through the designed computer program.

- The coach specify the lighting time for every flashing light individually in sec (expected time) it is required from the player to score a touch on the scoring unit that flashing light appear on it.

- The scoring unit consist of four strips every strip has a degree :

- The Strip close to coach blade 8 degree

- The next strip 6 degree

- The next strip 4 degree

- The last strip 2 degree

- If the specified time for lighting the stimulant ended and the player doesn't perform, the term (Fail) will be shown

- On touching the blade to scoring unit before the time finished, the performance time will be shown in $\mathrm{mm} / \mathrm{sec}$.

\section{Second: Performance Description :}

- The examiner stand on the combat distance (stretching arm Lunge- step and Lunge) according to coach instruction.

- The player take guard position in front of the coach or the designed electronic model.

- As the flashing light appear the player perform (stretch arm or Lunge or step and lunge) to score a touch with max speed and precision in performance and return once again to the guard position, then the second flashing light appear and so on till all the flashing light that the coach has saved on the computer finished. 
- In case that the coach is wearing the electronic jacket the coach take the role of positive or negative defender according to objective of measurement and player performance level.

\section{Out come from device :}

- Recording speed of every attacking skill performance the player do on $\mathrm{mm} / \mathrm{sec}$

- Recording precision degree of attacking skills performance for players

- Number of false execution

- Recording result for every player in a data base

- Printing a final report for player result immediately

\section{Performance rules:}

- The player must take the guard position before starting the test on the designed device

- The player must return to guard position after every attacking performance on the designed device.

\section{Statistical analysis:}

The data was statistically analysed by using "SPSS 22" program to calculate the following:

- Arithmatic mean

- Standard deviation

- (T) test for difference between two unrelated groups

- Person correlation coefficient.

\section{Conclusion and recommendation}

\section{First: Conclusion}

According to aim of research, sample used in applying the research, statistical analysis, research results the researcher conclude the following: 
1- Designing electronic device to measure speed and precision of attacking skills performance for fencing players

2- Confirming validity of the device in measuring attacking skills performance

3- Confirming stability of the device by Test-Retest

4- The designed device has a greater validity and stability degree in measuring speed and precision of attacking skill performance.

Second: Recommendations:

According to conclusion the researcher recommend the following:

1- Using the designed device in measuring speed and precision of attacking skills performance for fencing players in the training program.

2- Publicize (generalize) the device in physical education universities, clubs and olympic centers

3- Developing of the device to benefit from it more in serving the educational and training process.

4- Designing a different training program to train on the designed device to benefit from it in developing the skill performance for fencing players.

\section{Reference:}

Arabic reference:

1- Ebrahim Nabil Abd El Aziz: Technical aspects for fencing, book centerpub, Cairo, 2003.

2- Abd El Rahman Ahmed Abd El Rahman: "Suggested electronic device to identify some characteristic for strike blows to select junior boxing for competitions", Doctorate research, Faculty of physical education for boys, Alex Unv. 2006. 
3- Mohamed Hassn Alawi, Mohamed Nasr El Din Radwan: Measurement in physical education and sport psychology, Dar El Fekr, Cairo, 1996.

4- Mohamed Sobhi Hassanin: Evaluation and measurement in physical education, First part, $6^{\text {th }}$ ed, Dar El Fekr, 2004

5- Nabil Mohamed Ahmed FAwzi, Yasser Youssef: "Suggested device to develop motor response reaction in Judo". International Conference - Globalization and sport -first binder faculty of Physical education for boys, April 2001

6- Hani Mohamed Zakaria: "Design an electronic digital device to direct foot movement for the ideal performance for fencing players", Doctorate research, faculty of physical education, Banah Unv. 2010.

7- Wael Mohamed Shehatta: "Design a device to identity the electronic characteristic and strikes in kung Fu", Master research, faculty of physical education for boys, Helwan Unv. 2004. 